\title{
TOPICAL AUTOHAEMOTHERAPY- A NEWER MODALITY TO TREAT CHRONIC RECALCITRANT LEG ULCERS DUE TO VENOUS STASIS- A PILOT STUDY
}

\author{
Saravanan $N^{1}$, V. N. S. Ahamed Shariff2, Vivek Shah ${ }^{3}$, Nirmala $S^{4}$
}

${ }_{1}^{1}$ Associate Professor, Department of Dermatology, Chengalpattu Medical College. 2 Senior Assistant Professor, Department of Dermatology, Madras Medical College. ${ }^{3}$ Consultant Dermatologist, Sujay Hospital, Criticare Hospital and SRV Hospital, Mumbai. ${ }^{4}$ Professor, Department of Dermatology, Madras Medical College.

\section{ABSTRACT}

\section{BACKGROUND}

Leg ulcers due to venous stasis are recalcitrant to treatment in a number of patients, failing to respond to conventional therapies like limb elevation, compression bandaging and oral drugs such as pentoxyfylline; 13 such patients were selected and treated with topical autohaemotherapy once every week. Excellent response was noted with complete healing of ulcer within 3 - 7 weeks of initiation of therapy. Topical autohaemotherapy is a less invasive, cheap and effective therapy which acts as an adjuvant to limb elevation, compression bandaging and surgery for achieving rapid healing of venous ulcers as shown in this pilot study.

\section{KEYWORDS}

Autohaemotherapy, Leg Ulcers, Venous Ulcers.

HOW TO CITE THIS ARTICLE: Saravanan N, Shariff VNSA, Shah V, et al. Topical autohaemotherapy- a newer modality to treat chronic recalcitrant leg ulcers due to venous stasis- a pilot study. J. Evolution Med. Dent. Sci. 2017;6(22):1817-1819, D0I: $10.14260 /$ Jemds/2017/399

\section{BACKGROUND}

Leg ulcers in patients with chronic venous insufficiency are of common occurrence. They are primarily managed by limb elevation, compression bandaging and oral drugs like pentoxyfylline and diosmin. This is followed by vascular surgery once the ulcer has healed.(1) However, in a significant number of patients, the ulcer fails to respond to these therapies and frequently becomes a cause of significant morbidity to the patients. Topical autohaemotherapy provides an effective but cheap modality of therapy in such patients.

\section{MATERIALS AND METHODS}

This prospective and interventional pilot study was conducted between January and October 2013 in the Department of Dermatology, Madras Medical College and Rajiv Gandhi Government General Hospital, Chennai, India; 13 non-diabetic patients with chronic recalcitrant leg ulcers for more than 6 months duration proved to be due to venous stasis by lower limb venous duplex study were included in the study after proper consent, history taking and clinical examination. The patients with obviously infected wounds were excluded from the study. The patients included in study were put on topical autohaemotherapy once a week until resolution of ulcers. The ulcer and the surrounding skin was cleaned with normal saline and allowed to dry. Blood was drawn from a peripheral vein distant to the site of ulceration and uniformly applied all over the ulcer with a syringe.

Financial or Other, Competing Interest: None.

Submission 02-02-2017, Peer Review 04-03-2017,

Acceptance 10-03-2017, Published 16-03-2017.

Corresponding Author:

Dr. Vivek Shah,

Sujay Hospital,

\#25, Gulmohar Road,

Juhu, Ville Parle $(W)$,

Mumbai-400049.

E-mail: vivekkshah88@gmail.com

DOI: $10.14260 /$ jemds $/ 2017 / 399$
The amount of blood applied depended on the size and depth of the ulcer. The blood was allowed to clot over the ulcer, after which sterile dressing was applied over it and covered with roller bandage. The patient was instructed to keep the dressing in situ for 2 days, after which it was removed. The patient was asked to maintain local hygiene. The procedure was repeated at weekly intervals. Clinical photographs were taken prior to the initiation of therapy and at weekly intervals.

\section{RESULTS}

12 patients showed excellent response to therapy. Healthy granulation tissue was seen at the floor of the ulcer by 1 - 2 weeks with deposition of fibrous tissue starting from the periphery of the ulcer by 2 - 4 weeks. Complete healing of the ulcer within 3 - 7 weeks depending on the site, size and depth of the ulcer. The ulcer size in patients ranged from $2 \times 1 \mathrm{~cm}$ to $4 \times 3 \mathrm{~cm} ; 2$ patients on follow-up failed to show recurrence of ulcer even after 6 months post-therapy. A single patient with co-existing vasculitic disease failed to show significant improvement even after 8 sittings of topical autohaemotherapy.

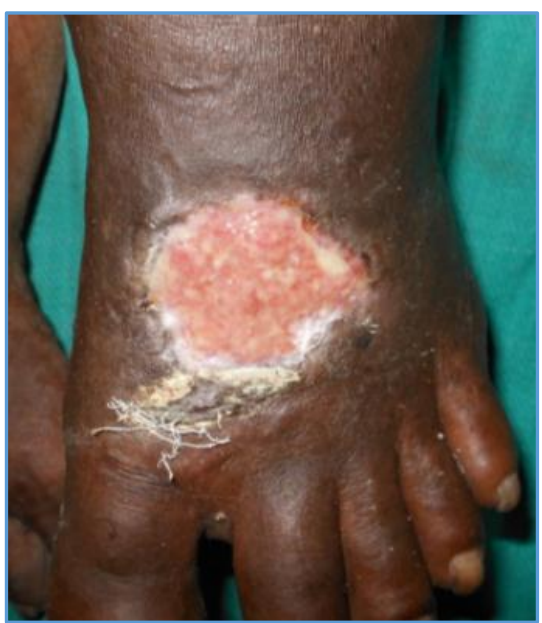

Figure 1. Pre-Procedure Photograph 


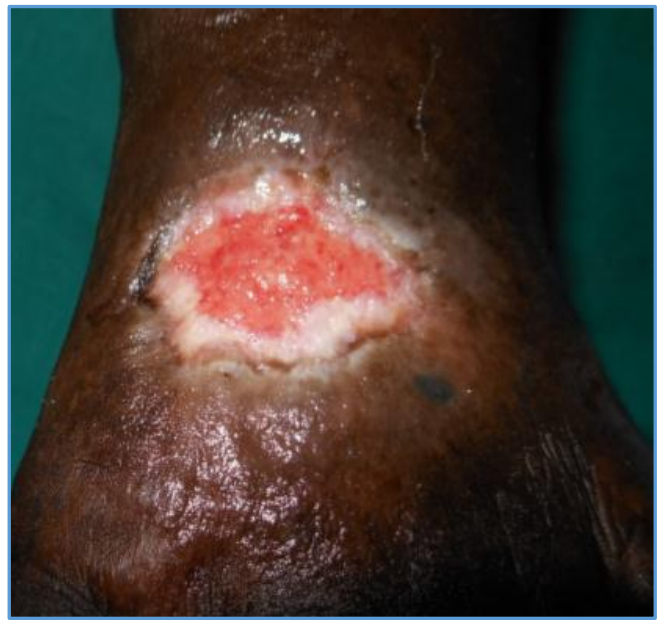

Figure 2. Ulcer with Healthy Granulation Tissue after 2 Sittings

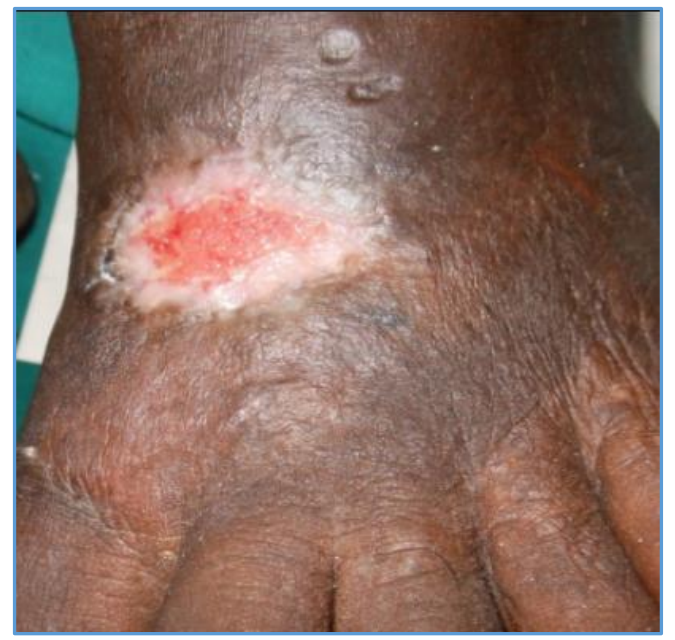

Figure 3. Ulcer with Marked Diminution in Size after 4 Sittings

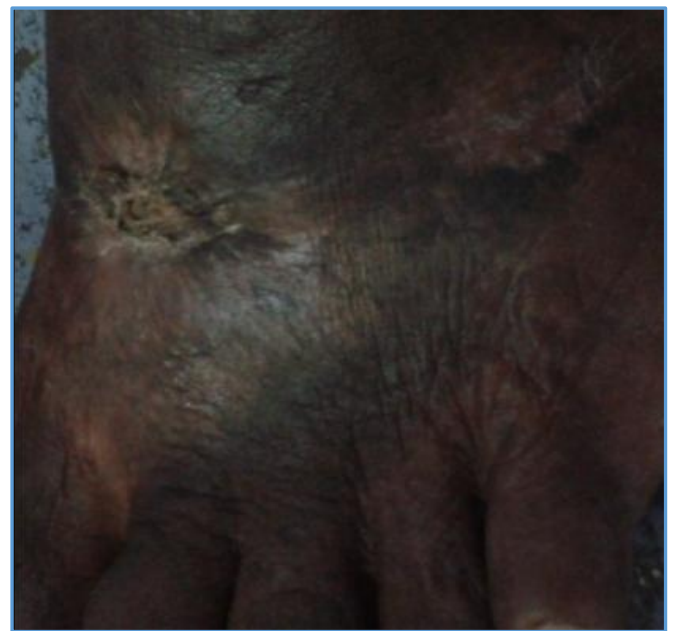

Figure 4. Completely Healed Ulcer after 7 Sittings

\section{DISCUSSION}

Chronically raised venous pressure due to venous incompetency leads to formation of a fibrin cuff around blood vessels with deposition of collagen IV around the blood vessels and collagen I and III in the dermis. This impairs diffusion of oxygen and nutrients into the surrounding skin leading to ulceration.
There is deposition of $\alpha 2$-macroglobulin in the perivascular cuff which sequesters growth factors like EGF, FGF and TGF- $\beta$ rendering them unavailable for the healing process to occur. $(2,3)$

Autohaemotherapy involves withdrawal of blood from the vein and the reinjection of the same blood back into a vein or through the skin or muscle. It is commonly pretreated with ozone prior to reintroduction in the body to achieve upregulation of the antioxidant mechanisms in the body. Modified topical auto-haemotherapy in our study did not involve any pretreatment with ozone, as the purpose of the therapy is to provide nutrients and growth factors for the healing process, lacking in the chronic venous ulcer. It correlates with the process of healing by secondary intention where a blood clot formed locally enhances the ability of tissue to heal by various mechanisms. It provides barrier to desiccation of wound and provides fibrin, which acts as a scaffold for cellular infiltrate. It also provides high concentration of growth factors like PDGF, $(4,5,6) \mathrm{EGF}$, TGF- $\beta$, $\operatorname{FGF}$ and $\operatorname{VEGF}(5,6)$ aiding epithelial regeneration, collagen synthesis and angiogenesis. $(4,5,6,7,8,9,10)$

$90 \%$ of the growth factors are released due to platelet degranulation during coagulation of blood within $1^{\text {st }}$ hour of therapy.(6) Platelets can synthesise additional growth factors for the remaining period of their viability. Autohaemotherapy also provides a high concentration of leucocytes locally providing a potent antimicrobial effect negating the need for topical or systemic antibiotics with therapy.(6) Topical autohaemotherapy is autologous and does not carry any risk of transmission of infections or allergic reactions. In comparison with platelet rich plasma which is also used for treating chronic leg ulcers, autohaemotherapy is less expensive and less time consuming. Platelet rich plasma therapy also requires a centrifuge, thrombin and calcium. Platelet rich plasma provides growth factors, whereas autohaemotherapy in addition to providing growth factors also provides a fibrin scaffold for cellular infiltrate and tissue healing.

\section{CONCLUSION}

Modified topical autohaemotherapy is simple, inexpensive and less invasive modality for treating recalcitrant leg ulcers due to venous stasis. This case series which proves its therapeutic effects needs to be extended to more patients and extensive trials with more number of patients and control groups should be conducted for confirming therapeutic protocol, modification using ozonation and comparison with platelet rich plasma. The results may be significant, especially in a resource poor country.

\section{REFERENCES}

[1] Simon DA, Dix FP, McCollum CN. Management of venous leg ulcers. BMJ 2004;328(7452):1358-62.

[2] Neumann HAM, Tazelaar DJ. Compression therapy. In: Bergan JJ, Goldman MP, (eds). Varicose veins and telangiectasias, diagnosis and treatment. St. Louis: Quality Medical Publishing Inc 1993:103-22.

[3] Neumann HAM. Measurement of microcirculation. In: Altmeyer P (edr). Wound healing and skin physiology. Berlin/Heidelberg: Springer Verlag 1995:115-26. 
[4] Knighton DR, Doucette M, Fiegel VD, et al. The use of platelet derived wound healing formula in human clinical trials. Prog Clin Biol Res 1988;266:319-29.

[5] El-Sharkawy H, Kantarci A, Deady J, et al. Platelet-rich plasma: growth factors and pro- and antiinflammatory properties. J Periodontol 2007;78(4):661-9.

[6] Smith RG, Gassmann CJ, Campbell MS. Platelet-rich plasma: properties and clinical applications. The journal of Lancester General Hospital 2007;2(2):73-7.

[7] Petrova N, Edmonds M. Emerging drugs for diabetic foot ulcers. Expert Opin Emerg Drugs 2006;11(4):709-24.
[8] Mehta S, Watson JT. Platelet rich concentrate: basic science and current clinical applications. J Orthop Trauma 2008;22(6):432-8.

[9] Senet P, Bon FX, Benbunan M, et al. Randomized trial and local biological effect of autologous platelets used as adjuvant therapy for chronic venous leg ulcers. J Vasc Surg 2003;38(6):1342-8.

[10] Eppley BL, Woodell JE, Higgins J. Platelet quantification and growth factor analysis from platelet-rich plasma: implications for wound healing. Plast Reconstr Surg 2004;114(6):1502-8. 